\title{
Organ donation after cardiocirculatory death following withdrawal of non-invasive positive pressure ventilation: a historical cohort study
}

\author{
J. Gordon Boyd, MD, PhD, FRCPC (1) - Michael Hartwick, MD, MEd, FRCPC • \\ Jeffrey M. Singh, MD, MSc, FRCPC · Karim Soliman, MD, FRCPC $\cdot$ Karen Hornby, MSc • \\ Beth Paltser, MSc $\cdot$ Lindsay Wilson, MHA $\cdot$ Andrew Healey, MD, RDCS, RDMS, FRCPC
}

Received: 6 September 2019/Revised: 5 December 2019/Accepted: 6 December 2019/Published online: 8 January 2020

(C) Canadian Anesthesiologists' Society 2020

\section{To the Editor,}

Approximately 4,500 Canadians are awaiting life-saving organ transplants, and many will die before receiving their transplant. ${ }^{1}$ In Ontario, the opportunity to donate organs has recently become available to individuals who choose to withdraw life-sustaining measures by discontinuing noninvasive positive pressure ventilation (NIPPV). The availability of transplantable organs from patients who die following withdrawal of NIPPV is unknown. We sought to describe potential donors transitioned to palliative care after being supported with NIPPV.

J. G. Boyd, MD, PhD, FRCPC ( $)$ · K. Soliman, MD, FRCPC

Department of Critical Care Medicine, Queen's University,

Kingston, ON, Canada

e-mail: Gordon.boyd@kingstonhsc.ca

Trillium Gift of Life Network, Toronto, ON, Canada

M. Hartwick, MD, MEd, FRCPC

Trillium Gift of Life Network, Toronto, ON, Canada

Division of Critical Care, Department of Medicine, University of Ottawa, Ottawa, ON, Canada

J. M. Singh, MD, MSc, FRCPC

Trillium Gift of Life Network, Toronto, ON, Canada

Toronto Western Hospital, University Health Network, University of Toronto, Toronto, ON, Canada

K. Hornby, MSc $\cdot$ B. Paltser, MSc $\cdot$ L. Wilson, MHA

Trillium Gift of Life Network, Toronto, ON, Canada

A. Healey, MD, RDCS, RDMS, FRCPC

Trillium Gift of Life Network, Toronto, ON, Canada

Critical Care Medicine, William Osler Health System, Brampton, ON, Canada
Patient data were obtained from Trillium Gift of Life Network (TGLN), the Ontario organ donation organization. Patients were included if they were being treated with NIPPV at the time of referral as potential candidates for organ donation. There were no exclusion criteria.

The identification and demographics of potential donors are shown in the Figure. From January 12017 to November 11 2018, 457 patients being treated with NIPPV were referred to TGLN for assessment of eligibility for organ donation. The majority of patients $(n=393,86 \%)$ were deemed medically unsuitable for donation by TGLN on the basis of chart review; and $64(14 \%)$ were eligible for approach. Twenty percent $(n=13)$ of eligible patients were not approached because the substitute decision maker (SDM) declined to speak with the TGLN team $(n=7)$, hospital policy or staff prevented approach $(n=2)$, no SDM was available $(n=1)$, or the SDM did not accept the palliative prognosis $(n=1)$. Of the 51 patients approached by TGLN for donation, the SDM provided consent for 23 $(45 \%)$. None of the patients were capable of providing firstperson consent for organ donation. The SDMs of 13 patients were approached about the possibility of organ donation after withdrawal of NIPPV, but these patients improved and survived.

Among the 23 individuals for whom consent for organ donation was provided, six (26\%) donated a total of 16 organs. For the remaining 17 patients, organs were not recovered because: no organs were accepted by the transplant program $(n=8)$, the SDM withdrew consent $(n=6)$, the donor developed organ dysfunction that precluded transplantation $(n=2)$, and the patient did not die in a time that allowed recovery with acceptable warm ischemia time $(n=1)$.

The number of eligible organ donors after withdrawal of NIPPV is low. With only $1.3 \%$ of referred patients going 
on to become organ donors, there is room for process improvement. Although the majority of referred patients were ruled out because their organs were unsuitable, we did identify potentially modifiable factors. The SDMs of seven potential donors refused to talk to TGLN; and 39\% of those that were approached declined permission to donate organs. The overall consent rate of $45 \%$ is lower than for deceased donation overall; the reported mean consent rate across 16 countries was $67 \%$ (range $31-90 \%$ ). ${ }^{2}$ Of note, hospital policy and/or staff prevented TGLN from approaching the SDM in two cases; this practice unfortunately disregards the end of life wishes of patients who may have registered their consent through the provincial registry $(33 \%$ of Ontario residents as of 2018). ${ }^{1}$ Unfortunately, the specific hospital policy or reason for staff preventing approach could not be identified in our study.

The SDMs of 17 patients went through the process of providing consent for organ donation, but their loved ones did not ultimately go on to donate their organs. The SDM for six of these potential donors withdrew their consent after initially agreeing to organ donation. It is possible that the delay to withdrawal of NIPPV incurred by the donation process was not acceptable to SDMs. This has been recognized in potential donors receiving invasive mechanical ventilation, as shorter intensive care unit
Figure Consort-style diagram illustrating total number of patients assessed for organ donation after withdrawal of non-invasive positive pressure ventilation, as well as a summary of the clinical and demographic characteristics of donors and non-donors. DCD = death determined by cardiocirculatory criteria; DNR $=$ do not resuscitate; $\mathrm{SD}=$ standard deviation; SDM = substitute decision maker; TGLN = Trillium Gift of Life Network; TSP $=$ transplant support physician; WLST $=$ withdrawal of life-sustaining therapy.

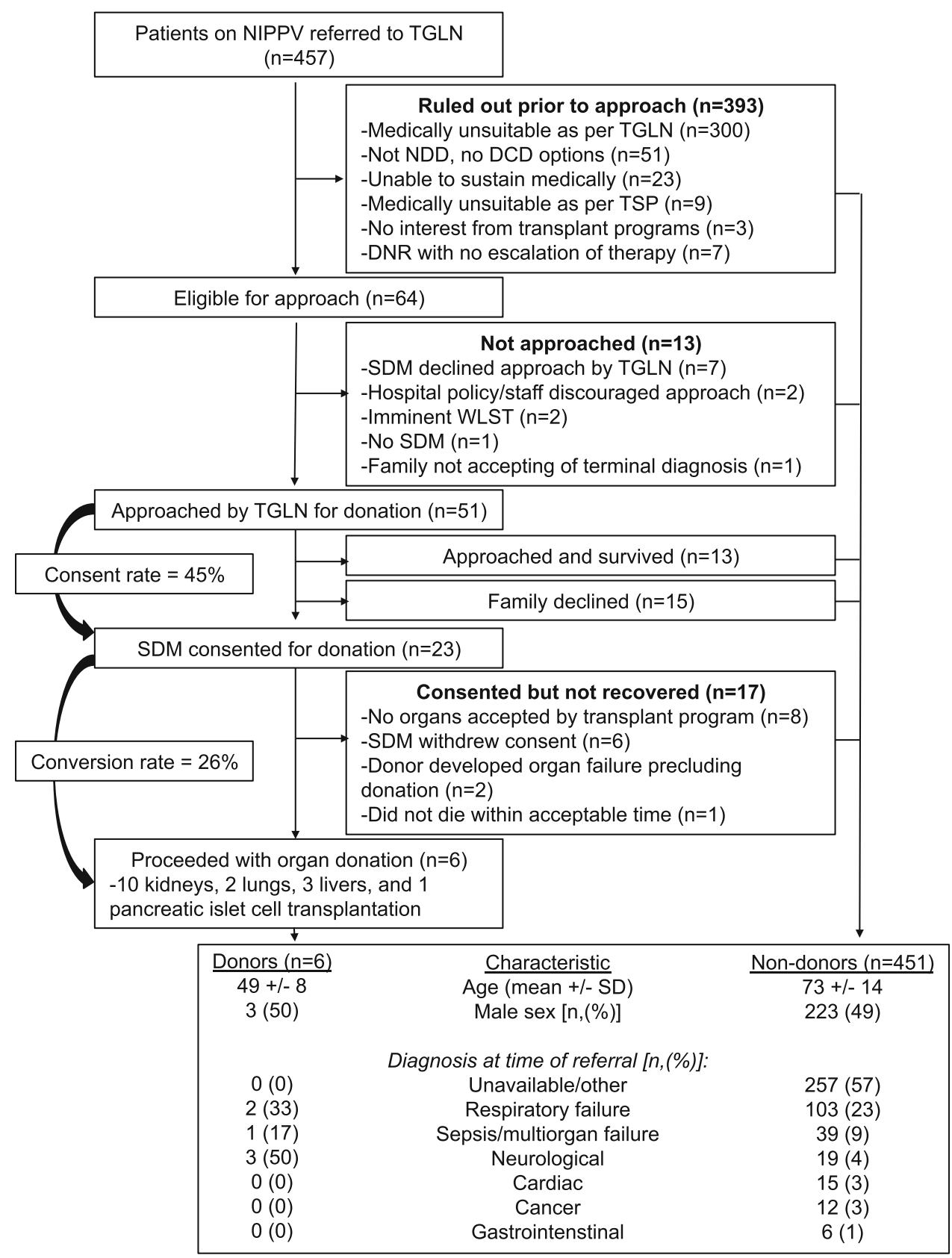


length of stay was independently associated with increased consent for organ donation. ${ }^{3}$ The remaining 11 patients did not go on to donate organs, despite SDM consent. This occurred for various reasons, such as progressive organ dysfunction precluding donation $(n=2)$ and organs not being accepted by transplant programs (i.e., no suitable recipients, $n=8$ ). Going through the process of consenting for organ donation, but not having a loved one successfully donate their organs has been described as a second loss for SDMs, both in the medical literature ${ }^{4}$ and in the lay media. ${ }^{5}$ Processes need to be in place to support the families whose decision to donate the organs of their loved one does not materialize.

Our data would suggest that we are imperfect at predicting imminent death or deterioration after withdrawal of NIPPV. For 13 of the 51 (25\%) SDMs who were approached for organ donation, the patient was coded as a survivor in our database. From a process perspective, organ donor coordinators would approach an SDM after the decision is made to withdraw life-sustaining therapy, to engage in a conversation about organ donation. There may be a delay between the initial approach and getting consent for donation. It is during this delay that the patient may have clinically improved to the point where the on-site donor coordinator no longer considers them a candidate for organ donation. Importantly, we have no data on the duration of their survival or their quality of life.

In summary, we have characterized the process of organ donation after withdrawal of NIPPV through Ontario's TGLN database. While the yield of organs may be low, offering donation to patients who have decided to discontinue NIPPV respects patient wishes and can save many lives.

Conflicts of interest None.
Funding statement J. Gordon Boyd receives salary support from the Southeastern Ontario Academic Medical Association New Clinician Scientist Program and research support from the Physician Services Incorporated New Investigator Program. He receives a stipend from the Trillium Gift of Life Network for his role as regional medical lead. Jeffrey M. Singh holds research funding from Physician Services Incorporated for research in deceased donation. He receives a stipend from the Trillium Gift of Life Network for his role as regional medical lead. Michael Hartwick receives a stipend from the Trillium Gift of Life Network for his role as regional medical lead. Karim Soliman receives a stipend from the Trillium Gift of Life Network for his role as regional medical lead. Karen Hornby is a salaried employee of Trillium Gift of Life Network as the manager of research support services. Andrew Healey receives a stipend from the Trillium Gift of Life Network for his role as chief medical officer.

Editorial responsibility This submission was handled by Dr. Sangeeta Mehta, Associate Editor, Canadian Journal of Anesthesia.

\section{References}

1. Trillium Gift of Life Network. Available from URL: https://www. giftoflife.on.ca/en/ (accessed December 2019).

2. Vincent A, Logan L. Consent for organ donation. Br J Anaesth 2012. https://doi.org/10.1093/bja/aer353.

3. Marck CH, Neate SL, Skinner MR, et al. Factors relating to consent for organ donation: prospective data on potential organ donors. Intern Med J 2015; 45: 40-7.

4. Sarti AJ, Sutherland S, Healey A, et al. A multicenter qualitative investigation of the experiences and perspectives of substitute decision makers who underwent organ donation decisions. Prog Transplant 2018; 28: 343-8.

5. Payne E. A gift ungiven: The anguish of losing a loved one can be compounded when their wish to be an organ donor can't be fufilled. Ottawa Citizen - Updated March 26, 2018. Available from URL: https://ottawacitizen.com/news/local-news/the-hope-andheartache-of-organ-donation (accessed December 2019).

Publisher's Note Springer Nature remains neutral with regard to jurisdictional claims in published maps and institutional affiliations. 